\title{
Monoparentalidad
}

\section{Lluís Flaquer}

Arbor CLXXVIII, 702 (Junio 2004), 345-376 pp.

\section{Introducción}

En todo el mundo occidental, somos testigos de una creciente preocupación por las graves consecuencias para los niños del aumento de la inestabilidad conyugal. Los divorcios y los nacimientos extramatrimoniales fueron relativamente raros hasta los treinta últimos años del siglo $\mathrm{XX}$. Por otra parte, la cohabitación vivió sus momentos más bajos durante los años cincuenta y sesenta en que prácticamente todo el mundo se casaba (Lewis, 2001). La dinámica del matrimonio y del divorcio experimentaron importantes cambios en los dos últimos decenios. El declive de la nupcialidad, la creciente incidencia del divorcio, el incremento de los hijos nacidos fuera del matrimonio y la aparición de nuevas formas de unión como las relaciones prematrimoniales y consensuales así como las parejas LAT (living apart together) constituyen las principales características de este nuevo escenario (Bégeot and Fernández-Cordón, 1997).

$\mathrm{El}$ crecimiento del divorcio se correlaciona con el auge de las sociedades postindustriales en las cuales se ha producido una enorme expansión del empleo femenino. La creciente participación femenina en el mercado de trabajo supone mayores oportunidades económicas y mayor autonomía para las mujeres, y no resulta sorprendente que ello comporte la elevación de las tasas de divorcio (Castles, 1998).

Sin embargo, las tasas de divorcio cada día reflejan menos la ruptura de parejas con hijos. Ya sea a causa del progreso de las rupturas conyugales de hecho, ya sea a causa del aumento del número de separaciones de parejas de hecho la tendencia hacia la desinstitucionalización del matrimonio ha comportado la proliferación de nuevas diversas formas de convivencia muy distintas de las pautas tradicionales de corte monolítico. De esta forma, los itinerarios vitales se han visto crecientemente di- 
versificados. Si tenemos en cuenta que muchas personas separadas se vuelven a casar o conviven con una nueva pareja que estuvo casada y que puede que tuviera también hijos, cada vez más niños crecen con un progenitor no consanguíneo (Beck and Beck-Gernsheim, 2002).

Este trabajo se divide en dos partes. En la primera se hacen una serie de consideraciones sobre el crecimiento de las situaciones de pobreza infantil en Europa en relación con el auge que está experimentando la monoparentalidad y cuáles podrían ser las mejores estrategias para combatirlas. En la segunda se exploran estas cuestiones en el caso de España a partir de los datos de investigaciones recientes.

\section{Monoparentalidad y pobreza infantil en una perspectiva comparada europea}

Existen pruebas de que el modelo de familia tradicional y las pautas tradicionales de formación familiar están perdiendo gradualmente su hegemonía en la mayoría de países occidentales. Gran parte de cambios en cuestión simplemente reflejan la aparición de formas alternativas de convivencia y formas más complejas de organizar la vida familiar de los individuos (González-López, 2002). Mientras que en las sociedades preindustriales la familia era sobre todo una comunidad de necesidad cuya cohesión era mantenida gracias a una obligación de solidaridad, en el mundo contemporáneo ha pasado cada vez más a primer plano la lógica de las vidas individualizadas. Así, pues, la familia se está convirtiendo en una relación electiva y en una asociación de personas individualizadas (Beck and Beck-Gernsheim, 2002). Los aumentos del divorcio, de la cohabitación y de los hijos nacidos fuera del matrimonio han contribuido todos ellos a la separación entre el matrimonio y la parentalidad (Lewis, 1999, 2001). El matrimonio es cada vez menos un acto de necesidad económica y cada vez más una cuestión de elección individual. Ello también significa la proliferación de nuevas formas de convivencia y de familia que son menos estables. Cada vez es más improbable que los niños pasen su entera infancia con su padre y su madre viviendo juntos. Todo ello refleja una mayor libertad de elección, pero también un riesgo y una inseguridad más elevados (Esping-Andersen, 2002a).

$\mathrm{El}$ análisis de la evolución de los coeficientes de variación de las tasas brutas de divorcio y de las proporciones de hijos extramatrimoniales muestra que desde 1960 se da un claro proceso de convergencia de la inestabilidad matrimonial y de las nuevas pautas de fecundidad en los 


\section{Monoparentalidad}

países de la Unión Europea (Figura 1) ${ }^{1}$. A pesar de un período de creciente divergencia durante los años setenta, un proceso de convergencia se impuso de nuevo a principios de los años ochenta. Desde entonces las dos curvas muestran tendencias parecidas con una mayor convergencia en lo que respecta al comportamiento divorcista (Cálculos propios a partir de datos de European Commission, 2002).

Figura 1. Coeficientes de variación de las tasas brutas de divorcialidad y de la proporción de hijos extramatrimoniales. EU-15, 1960-2000

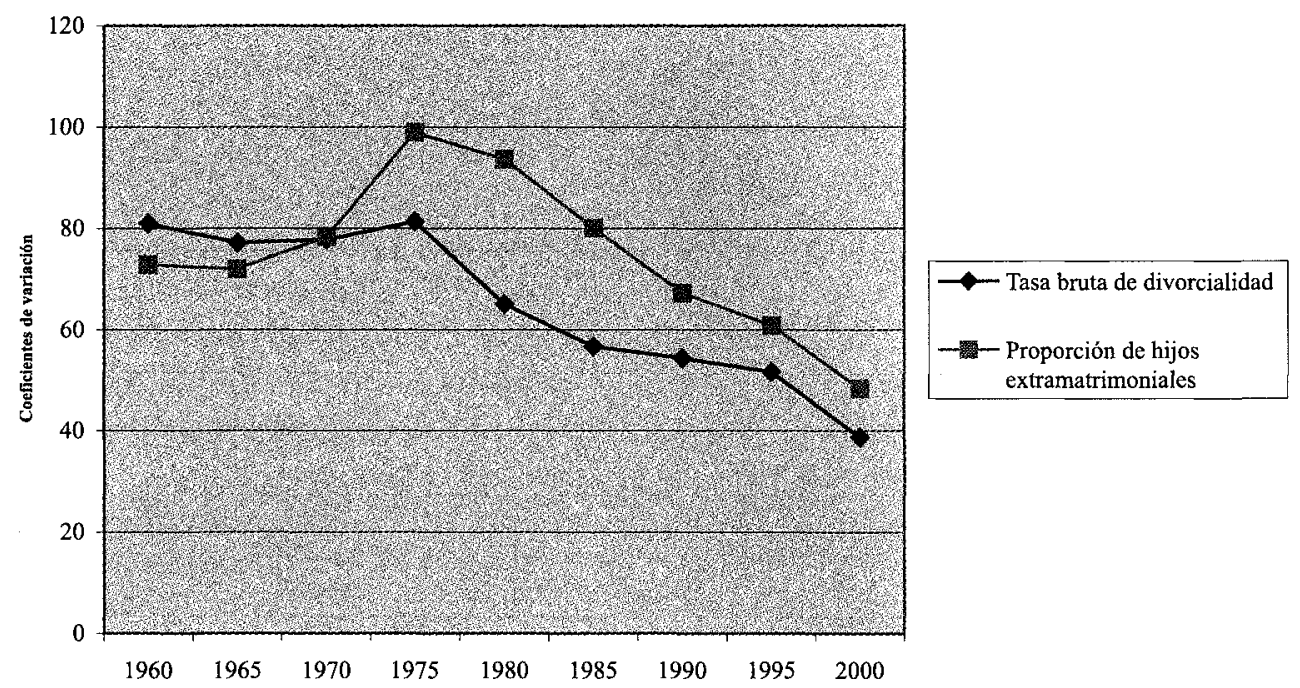

Fuente: Elaboración propia con datos de Eurostat

Aunque en algunos países europeos se ha dado una cierta pérdida de fuelle e incluso una estabilización de las tasas de divorcio en las últimas décadas, en otros están creciendo rápidamente. Mientras que los países nórdicos, Bélgica y el Reino Unido han liderado las tasas de divorcio durante bastante tiempo, ciertos signos nos indican que la ruptura matrimonial se está incrementando en la Europa del sur, a pesar del hecho de que parte de este crecimiento no se ve reflejado en las estadísticas oficiales.

Por otra parte, no se sabe gran cosa sobre las consecuencias del divorcio para los niños en los países candidatos a la Unión Europea, donde el desmantelamiento de muchas agencias de bienestar tras la caída del Telón de Acero pueden haber propiciado unas condiciones mucho más duras para ellos. De hecho, los países candidatos muestran mayores dispa- 
ridades sociodemográficas que los actuales Estados miembros de la Unión Europea. Así, en lo que respecta a la inestabilidad conyugal, en tanto que algunos países como las repúblicas bálticas, la República checa y Hungría presentan tasas brutas de divorcialidad muy altas, los valores para el resto de los países se sitúan por debajo de la media de la Europa de los 15 .

No obstante, especialmente en algunos países, el creciente número de progenitores solos se halla a menudo relacionado con el avance de la fecundidad extramatrimonial más que con el aumento de las tasas de divorcio. Irlanda constituye un buen ejemplo. Este país presentaba una de las mayores proporciones de menores de 16 años viviendo en familias monoparentales mucho antes de 1997 cuando se legalizó el divorcio. Los países con los porcentajes más elevados de madres solas con hijos a cargo con edades comprendidas entre 30 y 34 años son Suecia (12\%), Francia (12\%), Austria (11\%) y Alemania (9\%), mientras que en naciones como España, Italia y Bélgica las madres solas no llegan a representar más del $5 \%$ de las mujeres de este grupo de edad (González-López, 2002). Finalmente, si bien la incidencia de la pobreza infantil y de otras consecuencias adversas para los niños se reveló bastante alta entre las madres solas, no podemos ignorar que éstas también se pueden observar en formas de hogares más tradicionales como es el caso de las familias numerosas (Redmond, 2000).

Desde 1960 en que la proporción de nacimientos extramatrimoniales fue parecida en la Europa de los 15 y en Estados Unidos (en torno al 5\%), la posición de Estados Unidos ha sido mucho más avanzada de Europa (Figura 2). La composición heterogénea de la Unión Europea en términos del proceso de modernización y de las tradiciones culturales y religiosas probablemente explique este desfase. Así, a principios del siglo XXI, los países nórdicos, el Reino Unidos y Francia presentaban mayores proporciones de hijos nacidos fuera del matrimonio que Estados Unidos (European Commission, 2002). Las tasas de fecundidad de las chicas de 15 a 19 años están experimentando un descenso general, con una caída de casi dos tercios desde 1975. A pesar de una mejoría generalizada, todavía persiste una elevada fecundidad adolescente en el Reino Unido: en torno a 30 nacimientos por cada 1.000 chicas adolescentes desde 1975, en comparación con una tasa de 11 por mil en 1995 para el conjunto de la Unión Europea (Micklewright and Stewart, 1999). En lo que respecta a los países de reciente accesión a la Unión Europea (mayo de 2004), aunque Estonia, Letonia, Bulgaria y Eslovenia muestran una proporción muy elevada de hijos extramatrimoniales, los porcentajes de Chipre, Croacia o Polonia son bastante bajos. 


\section{Monoparentalidad}

FIGURA 2. Porporción de hijos extramatrimoniales. UE-15 y USA, 1960-2000

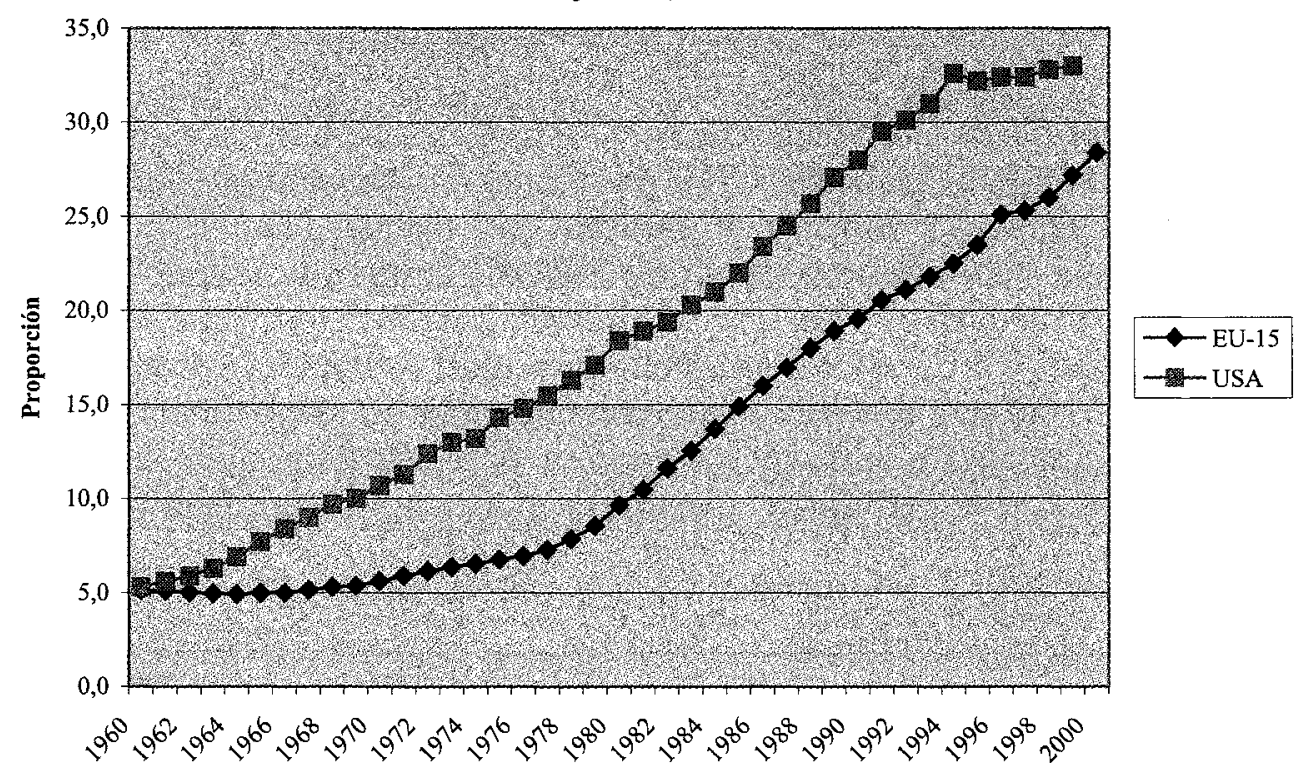

Fuente: Elaboración propia con datos de Eurostat

Las investigadoras feministas han considerado la monoparentalidad como una piedra de toque del tipo de tratamiento que brindan los Estados de bienestar a las familias en la medida en que las madres solas son potencialmente las principales cuidadoras y sustentadoras de sus hijos y lo que está en juego es su derecho a formar un hogar independiente sin el riesgo de verse abocadas a la pobreza y a la marginación. Existe una amplia variación de la medida en que las madres solas son identificadas públicamente como un problema social. Históricamente, bajo la lógica del modelo del sustentador masculino, las madres solas se convirtieron en un problema social porque carecían de dicho sustentador y, ello no obstante, tenían hijos que mantener. La dependencia de las madres solas de las prestaciones del Estado constituye hoy una animada cuestión política al hilo del intento de todos los gobiernos occidentales de reducir el coste de las prestaciones aportadas por el Estado y de trasladar una mayor responsabilidad de cara a la provisión social al mercado, a la familia y al tercer sector (Lewis with Hobson, 1997).

En el caso de las madres solas, existen tres principales posibles fuentes de ingresos: el padre no residente, el mercado de trabajo y el Estado. Las aportaciones de los padres son la fuente de renta menos importante 
para las madres solas en todos los países, pero los países divergen mucho en el grado de insistencia para que los padres paguen, en el tipo de legislación en vigor para obligarles a ello y en la medida en que el Estado garantiza el cobro de las pensiones de alimentos (Lewis with Hobson, 1997). En el Reino Unido los padres no residentes se han visto cada vez más sometidos a la atención de los organismos gubernamentales durante los años ochenta y noventa, en especial en lo relativo al derecho de familia y al mantenimiento de los hijos. En los últimos años el pago de sus pensiones de alimentos más que sus derechos de visita se ha convertido en la arena de contienda política más descollante y controvertida. Se estima que el contacto con el niño debería depender del pago de las pensiones de alimentos. Sin embargo, resta un debate sobre la importancia del contacto entre los padres no residentes y sus hijos (Bradshaw et al., 1999).

La medida en que la monomarentalidad es un estado más o menos transitorio constituye uno de los factores que afectan el bienestar de los niños. En este sentido, las segundas nupcias y la cohabitación se han considerado como vías de escape de la pobreza. El bienestar de los niños mejora en un grado muy considerable cuando las madres solas se vuelven a casar o forman una unión consensual, en cada uno de cuyos casos ello casi dobla los ingresos de su hogar (Hardey and Crow, eds., 1991; Morrison and Ritualo, 2000; Esping-Andersen, 2002b).

Una de las variables que más afectan la situación financiera de los niños que viven con madres solas es la participación de ellas en el mercado de trabajo. No existen pruebas de que el trabajo de las madres como tal sea pernicioso para el desarrollo infantil Por el contrario, cuanto mejor es su situación en el mercado de trabajo, más positivo es el influjo psicológico que ejercen sobre la familia. Los efectos del trabajo remunerado de las madres pueden ser muy positivos si tienen empleos gratificantes, pero hacerse negativos si sus empleos producen estrés y fatiga. Las madres sobrecargadas de trabajo pueden tener una influencia negativa sobre sus hijos, especialmente si ello se añade a empleos inseguros o estresantes, pero mucho peor es el desempleo (Esping-Andersen, 2002b).

Los ingresos del mercado desempeñan un papel más importante que las transferencias monetarias a la hora de explicar la diversidad de los resultados de los niños desfavorecidos en una perspectiva comparada (Vleminckx and Smeeding, eds., 2001). De hecho, la pobreza infantil a menudo se halla asociada con la precariedad laboral. Existen evidencias de una convergencia entre países en la medida en que hoy no existe ninguno en que no se espere que las madres solas trabajen (Lewis with Hob- 


\section{Monoparentalidad}

son, 1997). Ello no obstante, la proporción de hogares con niños en la Unión Europea sin un adulto ocupado aumentaron desde el 8\% en 1985 hasta más del $10 \%$ en 1996 , pese al hecho de que las tasas de desempleo oficiales permanecieron estables durante ese período. El Reino Unido presenta el peor registro: uno de cada cinco hogares con niños no tiene ningún miembro ocupado (Micklewright and Stewart, 1999).

Si bien el empleo de las madres constituye un factor primordial en toda medida política para combatir la pobreza infantil, ello no obsta para que las transferencias monetarias dejen de ser importantes. La provisión de servicios públicos de atención a las personas dependientes desempeña asimismo un papel determinante. Existe una línea divisoria entre los países en lo relativo al apoyo que se brinda a los niños; en los países nórdicos, las familias con hijos no tan sólo reciben transferencias de renta sino también el apoyo de una amplia gama de servicios sociales, mientras que en los países liberales el apoyo a las familias con hijos casi se limita enteramente a prestaciones bajo condición de recursos. Según parece, están creciendo las diferencias en las tasas de pobreza infantil entre los países de la OCDE y entre los distintos regímenes de bienestar. La pobreza de las familias con hijos a cargo es menos frecuente en los países nórdicos que en muchos otros países de la OCDE (Forssén, 1998). Mientras que en Escandinavia se ha reducido a un mínimo la pobreza infantil por medio de una estrategia combinada de espléndidas transferencias y de apoyo a las madres trabajadoras, en la Europa continental (así como en el Reino Unido) las familias dependen mucho más ya sea del sustentador masculino, ya sea de transferencias. La conciliación entre familia y trabajo a través de la generosa oferta pública de servicios de guardería (gratuitos o con una fuerte subvención) constituye una de las mejores formas de luchar contra la pobreza infantil, ya que el elevado precio de estos servicios puede ser un grave impedimento para las familias de clase baja, en especial para las mujeres con escasas cualificaciones educativas y para las mujeres con bajos ingresos (Esping-Andersen, 2002b).

La pobreza infantil asociada con la aparición de nuevas formas de convivencia familiares constituye una cuestión política de primera importancia. En los dos últimos decenios hemos sido testigos de nuevas modalidades de pobreza. Se ha dado un declive en la proporción de personas mayores entre los pobres y un aumento de su número entre los desempleados (especialmente los de larga duración), entre los jóvenes, los trabajadores inmigrantes y los progenitores solos (Cousins, 1999). Las investigaciones sobre la pobreza nos muestran que su imagen general ha cambiado en los últimos veinte años. No sólo la pobreza se ha feminiza- 
do, sino que también se ha 'infantilizado' (Forssén, 1998). Los niños, como grupo social, tienen un nivel de vida inferior tanto al de los adultos como de los padres y una probabilidad más alta de vivir en la privación relativa (Ringen, 1997). En algunas naciones la posición relativa de las familias con hijos a cargo se está deteriorando, tanto cuando se la compara con su posición monetaria de década anterior como cuando se la compara con la posición de otras categorías sociales (Esping-Andersen, 2002b).

En la Unión Europea existe una preocupación creciente por la pobreza de los niños y por la de las familias con niños. En la mayoría de países de la OCDE, la pobreza monetaria de los niños supera en la actualidad la de las personas mayores, que tradicionalmente constituían el grupo sociodemográfico con un mayor riesgo de pobreza (Jäntti and Danziger, 2000). En el Consejo Europeo celebrado en Lisboa en marzo de 2000, los líderes gubernamentales de los Estados de la Unión aceptaron una invitación de sus homólogos belga y británico, formulada en forma de llamamiento conjunto, para considerar el establecimiento de «estándares de calidad y procedimientos» (benchmarks and procedures) destinados a «abordar las complejas causas de la pobreza y de la exclusión social». Los niños fueron uno de los grupos que fueron señalados con signo de preocupación (Atkinson, 2000; Vleminckx and Smeeding, 2001).

En una conferencia sobre Beveridge pronunciada en Toynbee Hall en marzo de 1999 Tony Blair se comprometió a eliminar la pobreza infantil en los próximos veinte años (Bradshaw, 2000) ${ }^{2}$. Según Blair, uno de cada tres niños británicos vive en la pobreza. Los niños pobres tienen dos y media más probabilidades de no sacarse el graduado escolar. Las chicas de entornos desfavorecidos tienen diez veces más probabilidades que las de las familias acomodadas de quedar embarazadas cuando son adolescentes. Los niños pobres son más proclives a hacer novillos; a resultar excluidos de la escuela; a tener problemas con la policía; a vivir en un barrio marginal; a proceder de una familia de una minoría étnica; y a ser educados por un solo progenitor (Blair, 1999). En efecto, el Reino Unido es una de las naciones de la Unión Europea con mayores tasas de pobreza infantil. Otro de los países en que la pobreza infantil registra unas elevadas cotas es España, pero en nuestro país este tema todavía no forma parte de la agenda política.

Existe un acuerdo bastante fuerte sobre lo pernicioso de la pobreza infantil de tal modo que las medidas preventivas a menudo se justifican en aras de consideraciones morales. Sin embargo, su abolición se puede defender también en términos de eficiencia económica, competitividad in- 


\section{Monoparentalidad}

ternacional y mejora de la productividad. Es muy probable que los niños que crecen en familias desfavorecidas padezcan desempleo, cobren salarios bajos y experimenten problemas de salud en su vida adulta y que además leguen esta escasez de oportunidades a sus propios hijos (Vleminckx and Smeeding, 2001). Sabemos gracias a las investigaciones americanas que la pobreza infantil se halla fuertemente correlacionada con menos años de escolarización (dos años menos), más criminalidad, diversas patologías psicológicas y menores ingresos cuando los niños se hacen mayores. Es mucho más probable que los niños de familias pobres se conviertan en padres pobres más adelante y así reproduzcan el síndrome de la pobreza a través de las generaciones. Las oportunidades vitales en la sociedad de hoy permanecen enraizadas tan poderosamente en la herencia social como en el pasado. Contrariamente a lo previsto, la expansión del sistema educativo no logró debilitar el impacto de la herencia social. La disminución del impacto directo de los padres en el desarrollo cognitivo de los hijos constituye un elemento esencial de la nueva economía, en que los requisitos fundamentales de una buena vida, esto es, las aptitudes cognitivas y las cualificaciones profesionales, están aumentando cada vez más. Ello implica que las oportunidades vitales dependen de manera creciente del capital cultural, social y cognitivo que los ciudadanos pueden llegar a amasar. La fase vital fundamental se encuentra en la infancia y la cuestión crucial estriba en establecer la interacción entre las inversiones de los padres y de la sociedad en el desarrollo de los niños (Esping-Andersen, 2002b).

Los estatus profesionales elevados de los padres pueden influenciar las aspiraciones y las expectativas de empleo de los estudiantes y, a su vez, su compromiso con el aprendizaje como medio de satisfacción de dichas aspiraciones. Los estatus profesionales elevados de los padres también pueden ampliar el horizonte de opciones de las cuales son conscientes los niños. De hecho, los quinceañeros cuyos padres tienen empleos con estatus elevados muestran en término medio un mayor rendimiento en comprensión escrita, pero esta ventaja es mucho mayor en unos países que en otros. Si bien el estatus socioeconómico sigue siendo uno de los factores más poderosos que influencian en rendimiento escolar, algunos países demuestran que pueden ser compatibles una elevada calidad media y un alto nivel de equidad social en lo que respecta a los resultados escolares (OECD, 2002b).

No existe una tendencia generalizada en lo concerniente a la evolución de la pobreza infantil: algunos países registraron aumentos significativos mientras que otros -entre los que se cuentan los que muestran 
elevadas tasas de pobreza- registraron descensos. En la mayoría de los países, la pobreza infantil permaneció estable a lo largo de los últimos diez años. Los cambios en las tasas de pobreza se vieron poco afectados por las variaciones en la estructura de los hogares en términos de tipos familiares y situación laboral. Generalmente es mucho más probable que los niños sean pobres si conviven solo con su madre, pero las variaciones en las tasas de monomarentalidad no explican del todo las variaciones en la incidencia de la pobreza infantil de un país a otro (Vleminckx and Smeeding eds., 2001).

Con el aumento del número de madres solas los gobiernos se vieron enfrentados al dilema de tratarlas como madres o como trabajadoras. Históricamente aquellos países con una fuerte lógica del sustentador masculino tendieron a adoptar una elección dicotómica a ese respecto. Así, en el Reino Unido y en Holanda las madres solas fueron tratadas primero como madres y más adelante como trabajadoras. Sin embargo, en esos países se da una ambivalencia considerable a propósito del papel apropiado de las mujeres con niños pequeños que recientemente ha desembocado en una renovada insistencia en el papel de los hombres como sustentadores, si bien como padres biológicos, y no tanto como espososproveedores (Lewis with Hobson, 1997).

En Europa occidental se ha producido una substitución gradual del conjunto de supuestos basados en el modelo del sustentador masculino por un otro modelo inspirado en universalización de los adultos como sustentadores. El problema es que este nuevo modelo tiene un poder más prescriptivo que descriptivo y que no se corresponde con la realidad social de la misma forma que tampoco lo hacía el modelo del varón sustentador del pasado (Lewis, 2002b). La nueva forja de la relación entre trabajo y bienestar y la generalización de un modelo de bienestar «activo» tanto a las mujeres como los hombres no tiene porque ser inherentemente «malo» para ellas, pero requiere plantearse la necesidad de cómo abordar la cuestión de los cuidados a las personas (Lewis, 2002a). El avance hacia un modelo más individualizado implica un diferente conjunto de supuestos en que inspirar la estructuración de los Estados de bienestar.

Velar por el bienestar de los niños significa preocuparse por el futuro estado de salud de nuestros sistemas europeos liberales y democráticos. Se necesita una estrategia más preventiva que paliativa con el fin de promover la igualdad de oportunidades en la próxima generación, dado que la reducción de las desigualdades los adultos es más costosa, además de casi imposible, en la sociedad del conocimiento. Las inversiones en la primera infancia son efectivas desde el punto de vista de su coste (Danziger 


\section{Monoparentalidad}

and Waldfogel, 2000). Al igual que la educación, las políticas familiares pueden considerarse como una inversión en capital humano.

El Consejo Europeo reunido en Lisboa los días 23 y 24 de marzo del año 2000 celebró un encuentro especial para acordar un nuevo objetivo estratégico para Unión con el fin de fortalecer el empleo, la reforma económica y la cohesión social en una sociedad basada en la economía del conocimiento. El Consejo Europeo consideró que la meta global de estas nuevas medidas debería ser, a partir de las estadísticas disponibles, elevar la tasa de ocupación de un promedio del $61 \%$ actual para acercarse lo más posible al 70\% hacia 2010 e incrementar el número de mujeres ocupadas desde el 51\% actual hasta rebasar el $60 \%$ en las mismas fechas (European Commission, 2000). En caso de que se alcanzara esta meta probablemente crecería la inestabilidad conyugal, especialmente en los países del sur de Europa (y en algunos de los países candidatos), donde es más probable que tenga lugar el incremento del empleo femenino, si tenemos en cuenta que el divorcio se halla asociado con la independencia económica de las mujeres. Ello crea una situación de renovada preocupación por las consecuencias de la inestabilidad conyugal para los niños.

Está claro que la monoparentalidad o la inestabilidad conyugal en sí no constituyen las causas de la pobreza infantil o de otras secuelas adversas que puedan derivarse para los niños. Por esta razón, sería un grave error estigmatizar a las madres solas con hijos a cargo. Su bienestar y el de sus hijos depende de cómo los gobiernos enfocan las medidas destinadas a ellas y del grado en que existe un desajuste entre las estructuras sociales emergentes y las prestaciones y servicios existentes en los Estados de bienestar. En este sentido, la lógica política, es decir, los supuestos, principios y premisas subyacentes a los regímenes de bienestar adquiere una suma importancia. La definición de la lógica política que se necesita para una arquitectura de los Estados de bienestar más amigable para los niños contribuirá a abordar de una manera apropiada los retos y oportunidades que con que aquellos se enfrentan en su proceso de reestructuración.

Una de las paradojas de nuestro tiempo es que, si bien los costes de la pobreza infantil son muy altos, los costes de su erradicación serían bastante modestos. Si el objetivo es eliminar la pobreza en las familias con niños la estrategia basada en la provisión de servicios resulta claramente más costosa (y también menos eficaz) que la estrategia basada en las transferencias monetarias, pero es importante tener presente que ambas son interdependientes. España resulta un excelente ejemplo ilustrativo ya que combina unas tasas de pobreza infantil bastante elevadas 
con una baja tasa de empleo femenino y con un sistema de apoyo económico a las familias muy poco desarrollado. Por tanto, de cara a la comparación representaría el peor caso extremo. Los cálculos con simulaciones por medio de análisis de regresión indican que, en el caso de España, el empleo de las madres reduciría, pero no eliminaría, la pobreza. Si todas las madres trabajaran, la pobreza infantil llegaría a caer entre un $3 \%$ y un $4 \%$. Otra estrategia sería aumentar las transferencias monetarias hasta alcanzar el nivel necesario para que todas las familias con niños se situaran por encima de la línea de pobreza. El coste de esta medida representaría tan sólo el 0,16\% del PIB (Esping-Andersen, 2002).

\section{Algunas notas sobre la monoparentalidad en España}

Uno de los factores que explican el crecimiento de la nueva pobreza es el crecimiento de la inestabilidad conyugal en asociación con la transición del régimen familiar de un sustentador al de dos sustentadores. Este proceso de transición es consecuencia del incremento de la participación femenina en el mercado de trabajo, favorecida por diversos elementos, entre ellos la apuesta decidida de los gobiernos europeos a favor de este nuevo régimen.

El hecho de que, en nuestra sociedad, tienda a imponerse como norma entre las generaciones más jóvenes la familia con dobles ingresos, en parte como resultado del aumento de los niveles educativos de las mujeres, del imparable encarecimiento de la vivienda y de que su legitimidad reciba el espaldarazo de las instituciones trae consigo que los hogares con un solo sustentador, especialmente si están encabezados por mujeres con un bajo nivel de ingresos, experimenten mayores riesgos de caer en la precariedad económica.

Con ello las familias numerosas con hijos a cargo, que tradicionalmente habían estado relacionadas con elevados niveles de pobreza, ceden el paso a las familias monoparentales, que al tener por definición un solo sustentador se hallan en una situación de pobreza relativa superior a la de otros hogares. Si añadimos a ello que la práctica mayoría de hogares monoparentales están encabezados por mujeres y que en España éstas tienen tasas de paro, de temporalidad y de precariedad laboral superiores a las de los varones, así como salarios más bajos -la brecha salarial entre hombres y mujeres en España es una de las elevadas de la OCDE-, las probabilidades que tienen de caer en la pobreza, ellas y sus hijos, son mucho mayores. 


\section{Monoparentalidad}

A la espera de la próxima publicación de los resultados del Censo de 2001 según composición de los hogares, diversos indicadores atestiguan el rápido crecimiento de la monoparentalidad en España en los últimos años. Si medimos la ruptura a través de las cifras de separación y no de divorcio, en España las separaciones judiciales alcanzaron en 2001 el $31,5 \%$ de los matrimonios del año frente a un 36,6\% en la Unión Europea, superando con creces la media comunitaria algunas regiones como Cataluña con un porcentaje del $41,4 \%$. También parece estar creciendo mucho el número de separados de hecho (o sea aquellas personas que aparecen en el censo como casadas pero cuyas formas de convivencia son discordantes con respecto a su estado civil, ya sea porque viven solas, encabezan una familia monoparental o bien conviven en pareja con una persona que no está casada). Así, por ejemplo, los datos de la estadística de población explotados por el Instituto de Estadística de Cataluña revelan un crecimiento espectacular entre 1991 y 1996 no sólo de los divorciados, sino de los separados de hecho ( $184 \%$ en el caso de los hombres y $124 \%$ en el caso de las mujeres). El gran incremento experimentado por los separados de hecho podría indicar que la actual legislación del divorcio está desfasada, ya que no puede procesar adecuadamente todos los casos de ruptura que se están produciendo.

Por otra parte, aunque no sabemos gran cosa acerca de las rupturas informales de las uniones de hecho, podemos suponer que están aumentando atendiendo al incremento del porcentaje de los nacimientos fuera del matrimonio. Según datos correspondientes a 2001, casi uno de cada cinco niños (exactamente el 19,5\%) nació fuera del matrimonio, frente un $30 \%$ en el conjunto de los países de la Unión Europea. La gran mayoría de esos niños nace en el seno de parejas de hecho y gracias a investigaciones realizadas en otros países sabemos que dichas uniones son más frágiles que las conyugales.

Según datos recientes del Panel de Hogares de la Unión Europea publicados por Eurostat, España con mucho es el país de la Unión Europea en que más deprisa están creciendo las situaciones de monoparentalidad, tanto las generadas por rupturas matrimoniales como por los nacimientos de madres solteras (Figura 3). Preguntados los entrevistados que vivían en una familia monoparental con hijos dependientes, en que situación familiar se encontraban en el año anterior (2000), un $22 \%$ declararon que vivían en pareja con hijos y un 7\% que vivían solos (siendo la media europea tan sólo de un $13 \%$ y de un $3 \%$, respectivamente). Eso significa que casi tres de cada diez familias monoparentales de 2001 se crearon en los últimos doce meses, lo cual supone una tasa de crecimiento muy elevada en un año. 
Figura 3. Situación en qué se encontraban en el año anterior los progenitores solos con los hijos dependientes. Unión Europea, 2001

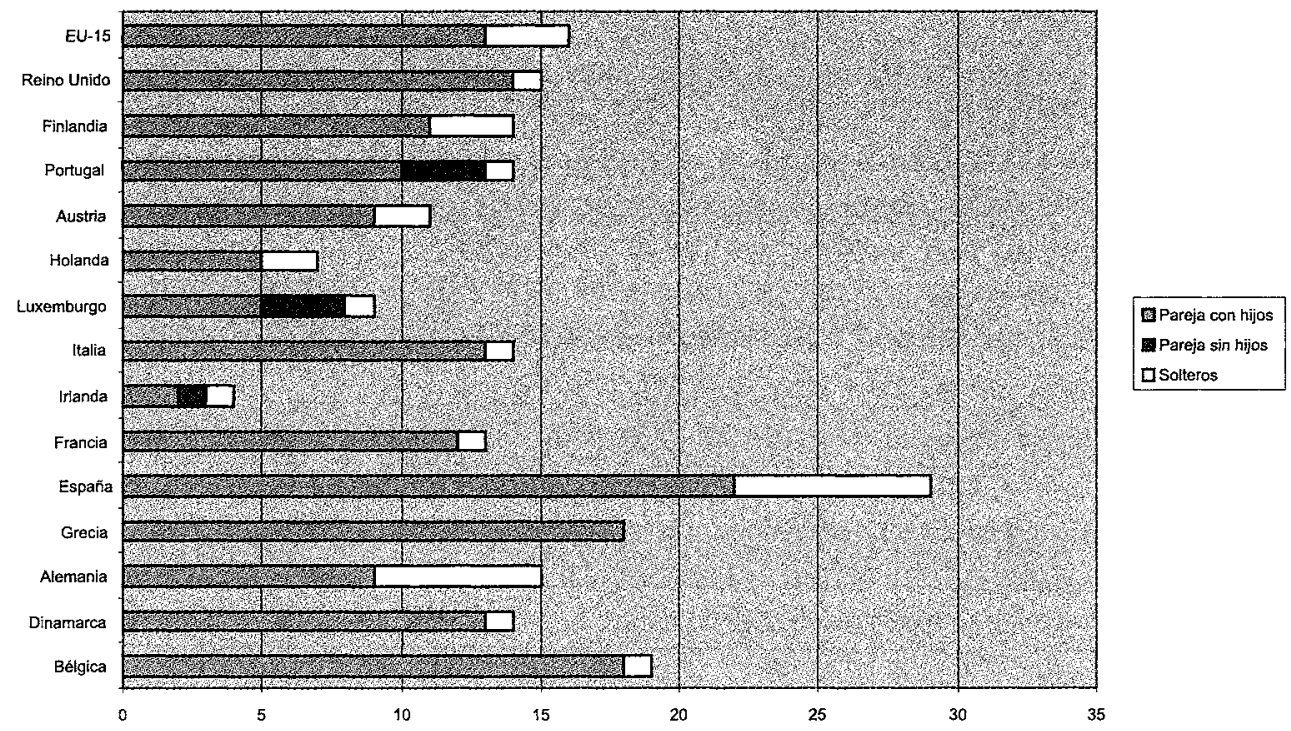

Fuente: Elaboración propia con datos del Panel de Hogares de la Unión Europea.

¿Por qué está creciendo la ruptura matrimonial en España? En primer lugar, por causas socioeconómicas. El trabajo remunerado de las mujeres les aporta una mayor autonomía económica y ello les da la llave de la ruptura en el caso de una relación insatisfactoria. En segundo lugar, y en asociación con el fenómeno anterior, parece darse un proceso de democratización de la ruptura. La separación y el divorcio dejan de ser un fenómeno selectivo en términos de clase (como hasta hace poco) y se democratizan en el sentido de que el acceso a la ruptura tiende a ser parecido en todos los sectores sociales.

Según investigaciones realizadas en algunos países como Italia o España ciertas categorías de la población, como las clases medias o las personas con elevados niveles de instrucción, son más propensas al divorcio (Barbagli, 1990; Solsona, Houle y Simó, 2000). En Italia, donde la estabilidad matrimonial ha sido siempre más elevada en los estratos más bajos que en los altos de la sociedad, la frecuencia de las separaciones legales tiende a aumentar a medida que se incrementan los niveles de instrucción (Barbagli y Saraceno, 1998). En España, son las personas con mayores niveles educativos las que mejor aceptan y asimilan la disolución del matrimonio, de tal forma que el divorcio afecta a la población de 


\section{Monoparentalidad}

manera selectiva (Solsona, Houle y Simó, 2000). Por el contrario, en naciones como Estados Unidos, las tasas de disolución matrimonial son mayores entre las clases populares, aunque hace unas generaciones en las sociedades occidentales las tasas de ruptura eran mayores según ascendíamos en la escala social (Goode, 1993).

En las últimas promociones matrimoniales de separados y divorciados, en España algunas variables individuales como el nivel educativo o la actividad económica influyen en gran medida en el acceso a la disolución matrimonial (Houle et al., 1999). En el caso de las mujeres separadas o divorciadas, dichas variables son todavía más determinantes que en el caso de los hombres. Mientras que los hombres registran niveles de actividad muy similares sea cual sea su estado civil, las mujeres separadas o divorciadas muestran tasas de ocupación más altas y tienen mejores empleos que las mujeres casadas. De hecho, en las investigaciones españolas sobre divorcio siempre se confirma que los niveles de actividad de las mujeres separadas o divorciadas son mucho más elevados que los de las casadas (Ruiz Becerril, 1999; Hernández Rodríguez, 1996; Borrrajo Iniesta, 1989; López Pintor y Toharia, 1989). En este sentido, el divorcio en España aparece como un fenómeno selectivo, siendo la independencia económica femenina uno de los factores individuales clave a la hora de decidirse por una disolución matrimonial (Solsona, Houle y Simó, 2000).

¿Por qué las categorías sociales elevadas son más propensas al divorcio en los países del sur de Europa? En naciones como España e Italia, hallamos claramente un efecto de género. En la última década, la participación en el mercado laboral de mujeres y hombres ha sido muy diferente, dependiendo de sus niveles educativos. Mientras que las tasas de actividad económica para los hombres y mujeres con niveles educativos elevados son bastante parecidas, las mujeres con un menor grado de educación presentan una tasa de actividad mucho más baja.

En general, en los países de la OCDE, el diferencial entre las tasas de ocupación masculinas y femeninas tiende a ser escaso en el caso de los niveles educativos altos, pero en el caso de los bajos puede ser considerable. En España, sin embargo, el diferencial entre las tasas masculinas y femeninas alcanza 45,1 puntos para los niveles educativos bajos (sólo detrás de Italia y Grecia, siendo la media de la OCDE 22,4 puntos), mientras que para los niveles educativos altos es todavía de 14,8 puntos, el diferencial más elevado para los países de la OCDE, con la única excepción de Japón y Corea (Comajuncosa, Escobedo, Flaquer, Laborda, Obeso, et. al., 2004). 
Por tanto, cabría esperar un probable desarrollo de los comportamientos divorcistas en aquellos países como España o Italia en que el empleo femenino tiene margen para crecer y en que el divorcio, antes un fenómeno selectivo reservado para las clases medias y altas, se está convirtiendo en un comportamiento cada vez más interclasista (Goode, 1993; Solsona, Houle and Simó, 2000).

Sin embargo, los estudios citados se hicieron con datos de 1990. Hasta la fecha todavía no se ha intentado demostrar fehacientemente la tesis de la «democratización del divorcio» con datos más recientes. Es cierto que el importante crecimiento de las tasas de ruptura que se ha estado comentando está apuntando en esa dirección. No podría crecer tanto la ruptura si siguiera confinada a las capas medias altas. No obstante, falta llevar a cabo análisis más precisos con datos de los años noventa, esperando poder disponer pronto de los resultados de censo de 2001 según la composición de los hogares. En este trabajo se analizan algunos datos recientes procedentes de la Encuesta de Población Activa, del Panel de Hogares de la Unión Europea y de la Estadística de Población de Cataluña (1991-1996), en la medida en que pueden contribuir a arrojar luz sobre los cambios en curso.

La Figura 4 sobre la evolución entre 1996 y 2001 de la proporción de personas casadas y separadas o divorciadas según nivel de instrucción muestra que los casados arrojan porcentajes más altos que los separados y divorciados en el caso de los niveles educativos más bajos (hasta estudios primarios, incluyendo a los sin estudios y analfabetos), mientras que en el caso de los estudios medios (hasta primer nivel de enseñanza secundaria) sucede todo lo contrario. Desgraciadamente no se pudo incluir en el análisis a las personas con estudios postobligatorios porque los datos del Panel de Hogares no eran significativos para esas categorías. Esta distribución podría indicar que la ruptura matrimonial se produce ya en los últimos años en los niveles educativos medios y no en los altos cómo sucedía anteriormente. Desgraciadamente al no disponer de una serie anterior a 1996 no se pueden sacar conclusiones válidas sobre cuándo se produjo el posible cambio de tendencia.

Una segunda aproximación al fenómeno podría ser a partir de la relación con la actividad. Es bien sabido que la actividad económica de las mujeres separadas o divorciadas es superior a la de las casadas. Ello se explica fácilmente en un país como España donde las ayudas a las familias monoparentales han brillado por su ausencia en los últimos años. Las mujeres que deciden separarse son ya activas o, en caso que no lo sean, es probable que pronto lo sean. Pero, ¿ha sido siempre así? ¿Se están produciendo cambios al respecto en los últimos años? 


\section{Monoparentalidad}

Figura 4. Evolución de la proporción de personas casadas y separadas/divorciadas con nivel de estudios primarios o inferior y con primer nivel de enseñanza secundaria España, 1996-2001

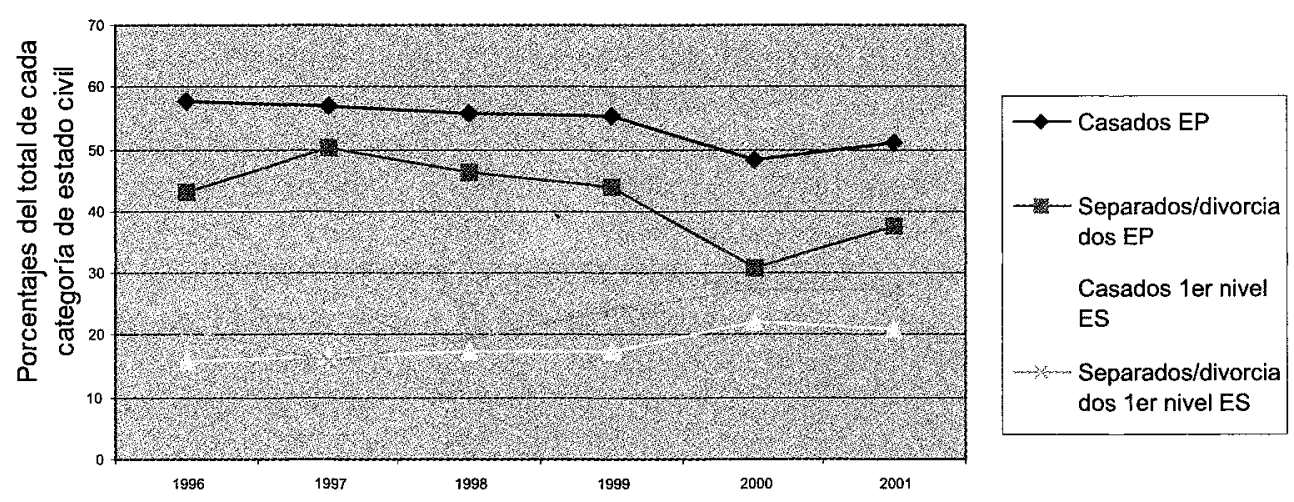

Fuente: Elaboración propia con datos del Panel de Hogares de la Unión Europea publicados por el INE.

La Figura 5 muestra la tasa de actividad de las mujeres de 30 a 49 años (cuando es probable que tengan hijos a cargo) por estado civil. El gráfico muestra una gran estabilidad desde 1987 en el caso de las mujeres solteras y separadas o divorciadas frente a la de las mujeres casadas o viudas. Las mujeres separadas y divorciadas tienen tasas de actividad muy parecidas a las de las solteras, muy superiores en ambos casos a las de las casadas y viudas, que a pesar de ello registran aumentos significativos a lo largo de los últimos 15 años. Sin embargo, entre un 15\% y un $20 \%$ (en distintos puntos del período considerado) del total de mujeres separadas o divorciadas son inactivas.

El hecho de que entre un $80 \%$ y un $85 \%$ de las mujeres separadas y divorciadas sean activas no les garantiza un empleo. Veamos pues cuáles son sus niveles de ocupación y sus tasas de desempleo.

En la Figura 6 aparecen los datos más detallados que se han podido analizar hasta la fecha. No se trata de datos muestrales sino censales y por tanto exhaustivos, por lo que se da un margen para la desagregación muy superior al existente en el caso de las encuestas. Corresponden a la estadística de población de Cataluña (equivalente al censo) para los años 1991 y 1996 y registran las tasas de ocupación de las madres con hijos a cargo menores de 16 años en función de su estado civil, incluyendo las separadas de hecho (o sea, aquellas madres que siendo casadas encabezan un núcleo monoparental). Igualmente se ha añadido la categoría de las casadas que viven con su pareja para facilitar el contraste entre las di- 
versas situaciones de monoparentalidad con el grueso de las madres que tienen hijos cargo formando parte de núcleos biparentales.

Figura 5. Tasas de actividad por estado civil. Mujeres de 30-49 años España 1987-2003

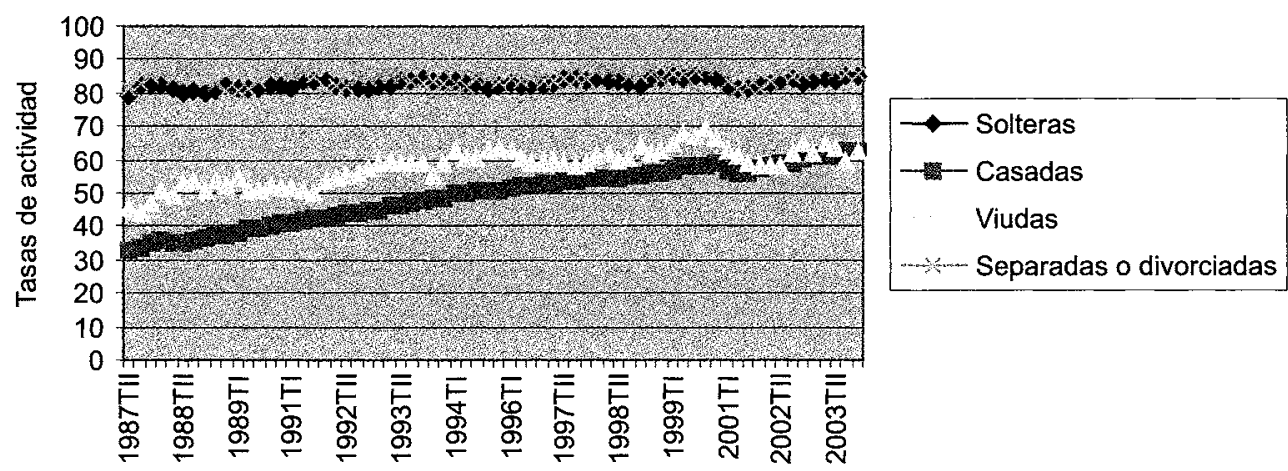

Fuente: Elaboración propia con datos de la EPA.

El análisis de los datos que muestra la Figura 6 revela que las madres que viven en núcleos monoparentales, con excepción de las viudas, tienen tasas de ocupación mucho más elevadas que las casadas, que presentan unas tasas parecidas a las de aquéllas. En segundo lugar, la tendencia evolutiva entre 1991 y 1996 de las madres que viven en núcleos monoparentales y biparentales es bastante distinta. Con excepción de las viudas (que una vez más tienen un comportamiento parecido al de las casadas) y de las separadas de hecho (cuya tasa prácticamente no varía entre 1991 y 1996) todas las madres solas presentan menores tasas de ocupación en 1996 que en 1991. Así, la tasa de ocupación de las madres solteras decrece en un $14 \%$, la de las separadas en un $11 \%$, la de las divorciadas en un $10 \%$, al tiempo que permanece estable la de las separadas de hecho y crece en un $3 \%$ la de las viudas y en un $15 \%$ la de las casadas.

En un primer momento, podríamos pensar que el descenso del nivel de ocupación de las madres solas es resultado del aumento del paro. En efecto, las tasas de desempleo de las madres solas en su conjunto es muy superior al de las madres casadas que viven en pareja: mientras que entre 1991 y 1996 las de éstas pasan del 22,3\% al 25,6\%, las de las madres solas pasan del $23,6 \%$ al $28,6 \%$. Las tasas de desempleo más elevadas en 1996 son las de las madres solteras $(39,6 \%)$, así como las de las separa- 
das (29\%), que ambas están por encima de la media de las madres solas. Las tasas de desempleo que más crecen durante el quinquenio son las de las divorciadas (34\%), las de las viudas (29\%), las de las separadas (28\%), las de las solteras (16\%) frente a sólo un $1,5 \%$ en el caso de las separadas de hecho o un $15 \%$ en el caso de las casadas.

Figura 6. Tasas de ocupación de las madres con hijos menores de 16 años según su estado civil y situación de convivencia Cataluña 1991-1996

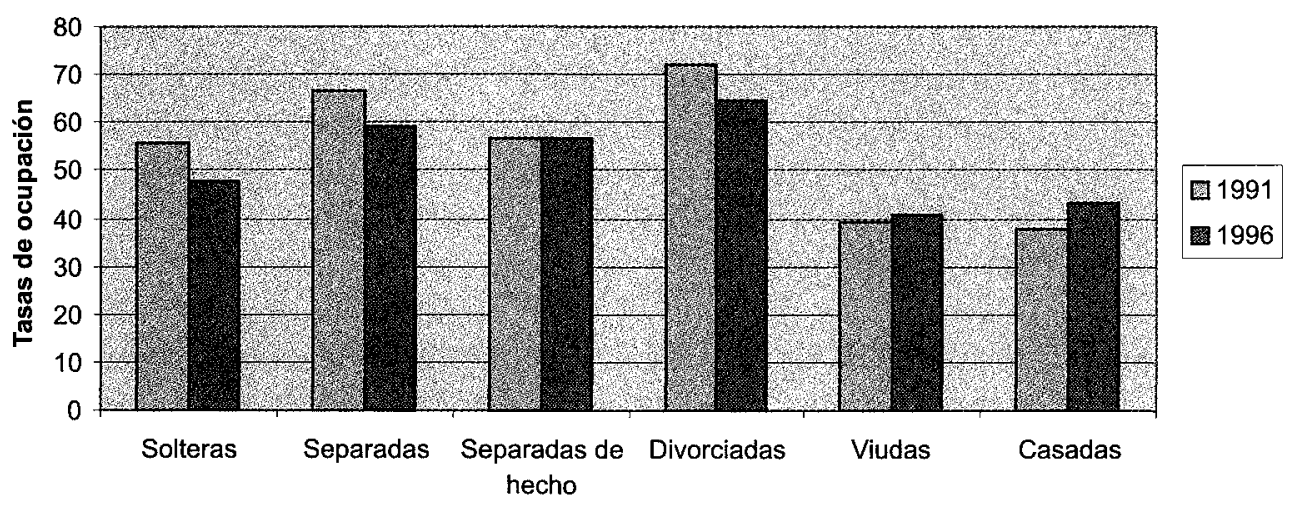

Fuente: Elaboración propia cond atos del IDESCAT.

Pero las tasas de ocupación de las madres solas descienden porque, en casi todas sus categorías, se produce también una disminución en sus niveles de actividad. Mientras que la tasa de actividad de las madres casadas aumenta en 9,7 puntos de porcentaje, la de las madres solas en su conjunto sólo lo hace en 0,7 . Las categorías en que producen descensos más acusados son las madres solteras ( 5,1 puntos), las separadas $(2,4)$, las divorciadas $(1,9)$. Por el contrario, las separadas de hecho aumentan en 0,1 puntos y las viudas en 5,3 .

En el caso de los padres solos aparecen también tendencias dignas de mención. En primer lugar, tanto sus tasas de actividad como de ocupación, con ser muy superiores a las de las madres solas, son inferiores a las de los padres que viven en pareja, cuyo nivel de actividad se aproxima al cien por cien. Así, el diferencial de las tasas de actividad de los padres de los núcleos biparentales con respecto a los de los monoparentales pasó de 5,5 puntos de porcentaje en 1991 a 7,5 en 1996. En lo que respecta a las tasas de ocupación este mismo diferencial pasó de 10,3 en 1991 a 12,6 en 1996. 
Lo mismo sucede en las tasas de paro. Con ser inferiores a las de las madres solas, las de los padres solos son muy superiores a las de los padres que viven en pareja. En este caso, los diferenciales -ahora negativostambién tienden a aumentar a lo largo del período 1991-1996, pasando del $-5,6$ al $-6,5$.

A la hora de explicar todos esos resultados cabe ser prudente e interpretarlos con cautela. Ante todo, no podemos estar seguros de que las tendencias observadas en el período 1991-1996, con una evolución muy desfavorable del desempleo, sean las mismas del final de los años noventa, con descensos muy importantes de los niveles de paro. Además, tampoco se puede asegurar con rotundidad que los comportamientos que aparecen en Cataluña sean parecidos a los existentes en otras partes de España. Por último, cabe tener presente que se trata de una investigación en marcha, cuyos resultados no son todavía definitivos.

En todo caso, sí que está claro que esos resultados nos indican que las familias monoparentales resultan más vulnerables ante el crecimiento del desempleo, con las consecuencias negativas que ello puede tener para sus niveles de renta y los de sus hijos. No sabemos, sin embargo, si ello sucede porque trabajan en sectores más afectados por la crisis económica, resultan más discriminadas por los empresarios al buscar trabajo o porque al tener niveles educativos bajos tienen mayores dificultades a la hora de encontrar empleo.

En la Figura 7 se advierte que las tasas de paro de las madres solas con hijos a cargo son superiores a las de la media de las mujeres de 30 a 49 años. A pesar de que descienden significativamente las tasas de paro, a lo largo del período 1994-2003 se mantiene la tendencia apuntada, aunque parece que hacia el final se produce una cierta convergencia. Estos datos indicarían que esta mayor vulnerabilidad de las madres solas se da incluso en épocas de bonanza económica y por tanto es independiente del ciclo.

¿Cómo se puede interpretar el descenso de la actividad de las madres solas separadas, divorciadas y solteras entre 1991 y 1996? De la misma forma que el descenso del paro puede hacer aumentar la actividad, la disminución de la actividad puede ser consecuencia del incremento del paro. Ante la dificultad de encontrar empleo, puede cundir el desánimo y una de las consecuencias de ese desánimo puede ser el abandono de la actividad. Como se puede observar en la Figura 8, hasta 1994 los separados y divorciados mostraban tasas de desánimo inferiores a a las de otras categorías de estado civil; a partir de esa fecha sucede todo lo contrario y, a pesar de que con el tiempo va descendiendo la tasa de desánimo de todas las categorías, se convierten en los más desanimados de todos, inclu- 


\section{Monoparentalidad}

so por encima de los casados. Estos datos podrían ser indicativos de que, en la segunda mitad de los años noventa, siguen las dificultades de los separados y divorciados para encontrar empleo. Además, podrían representar un aval para la confirmación de la tesis de la democratización del divorcio.

Frgura 7. Evolución de las tasas de paro de las madres solas y de las mujeres de 30 a 49 años. España, 1994-2003

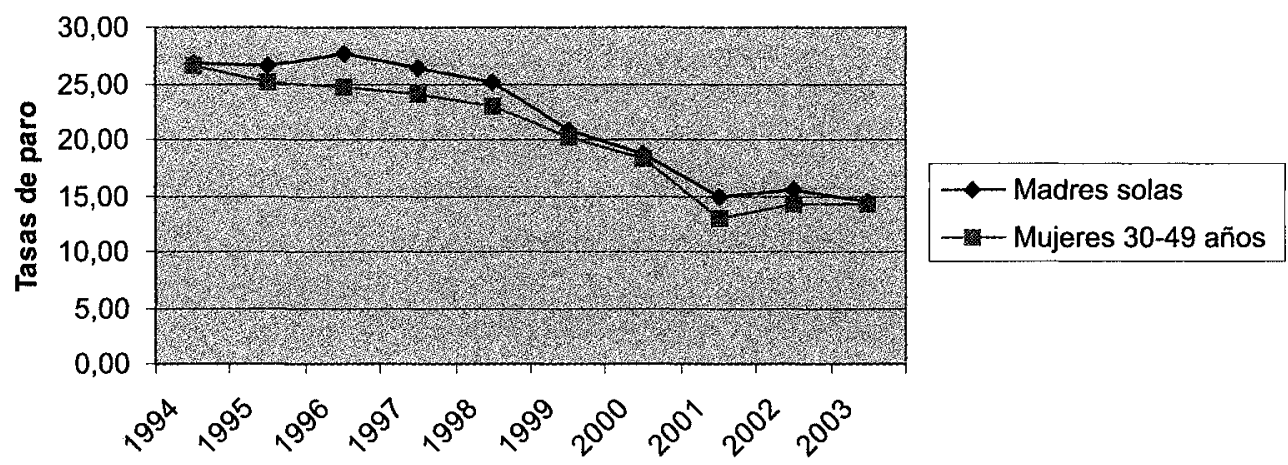

Fuente: Elaboración propia con datos de la EPA.

Una característica común de mujeres casadas y viudas es que, en principio, disponen de ingresos alternativos (en el caso de las primeras, los de su pareja y las segundas, su pensión) y, por ello, pueden ser más selectivas a la hora de buscar un empleo. Ello supone no tener que aceptar trabajos con contratos precarios, temporales o eventuales, con mayores probabilidades de quedarse en paro, frente a las madres solas solteras, separadas o divorciadas que, al tener una escasa o nula protección social y no estar respaldadas económicamente por su cónyuge, sí se ven obligadas a ello. Si esta interpretación fuera correcta, la mayor necesidad de ingresos de las madres solteras, separadas y divorciadas frente a las casadas y viudas explicaría su distinto coportamiento ante el mercado de trabajo. Teniendo en cuenta que las madres separadas de hecho, en principio en trámite de separación legal, se hallan en proceso de transición de un grupo a otro, no resulta extraño descubrir que también los comportamientos que presentan se encuentren a mitad de camino entre los de un grupo y otro.

En todo caso, esos resultados serían indicativos de que el distinto tratamiento por parte de las políticas sociales que reciben unas familias mo- 
noparentales frente a otras (en especial, las encabezadas por solteras, separadas y divorciadas frente a las viudas) condicionan su comportamiento en el mercado de trabajo y tienen consecuencias importantes con respecto a sus niveles de bienestar y los de sus hijos.

Figura 8. Desanimados por estado civil con respecto al total de los efectivos de cada grupo. España, 1987-2002

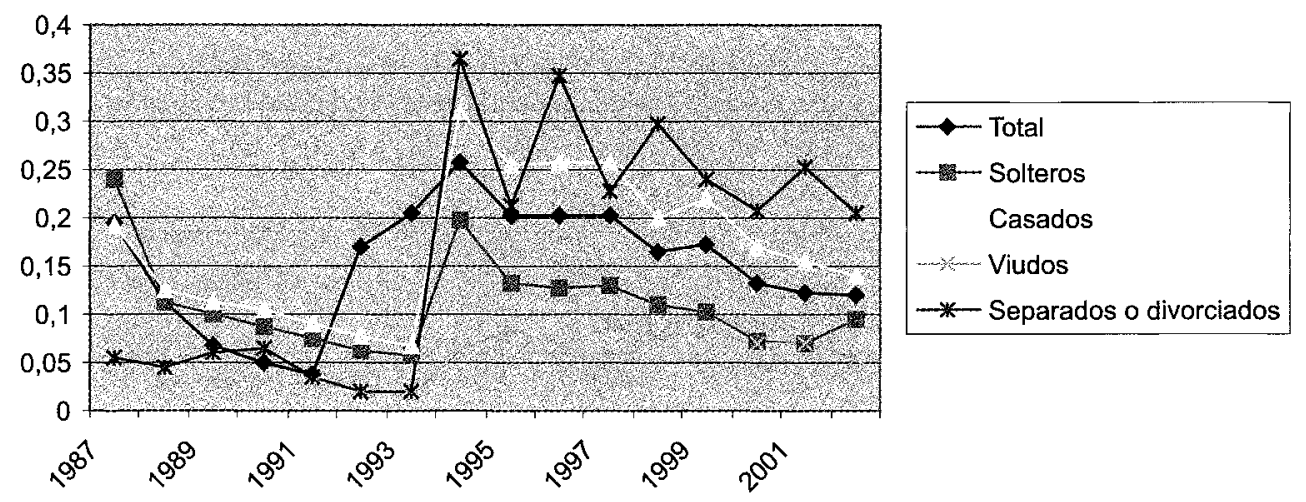

Quedan muchas preguntas por contestar y es preciso seguir indagando para poder dar una respuesta satisfactoria a muchos interrogantes. Por ejemplo, ¿cuáles son las fuentes de ingresos de las mujeres inactivas y/o desempledas? ¿Qué contribución supone para los ingresos de las familias monoparentales la pensión compensatoria o de alimentos de lso ex-cónyuges? ¿Qué relación existe entre los distintos tipos de monoparentalidad y los niveles de pobreza observados?

La tendencia hacia una creciente inestabilidad conyugal apunta en la dirección de un aumento del riesgo de pobreza infantil. Si en las sociedades europeas de hace cincuenta años la pobreza monetaria estaba asociada con las personas mayores, ahora son las familias con hijos a cargo las que se encuentran en mayor peligro de exclusión social. En especial, son las familias monoparentales (además de las numerosas o de las de un solo sustentador) las que afrontan mayores riesgos de pobreza.

Un estudio reciente ha estimado que en Cataluña hay unos 105.000 menores de 16 años pobres, lo cual representa el $11 \%$ de la población infantil catalana. Estos niños residen en 60.000 hogares, en los cuales conviven unas 260.000 personas. Más de la mitad viven en hogares que podrían encuadrar en la pobreza extrema. La pobreza de tres cuartas partes de los hogares pobres catalanes es independiente del ciclo económico y tiene raíces estructurales. 


\section{Monoparentalidad}

Una parte de la pobreza infantil se concentra en familias monoparentales. Se trata de unos 44.000 hogares y representan el $15 \%$ del total. Además, el gasto equivalente de los hogares encabezados por un progenitor solo tiende a ser más bajo que la media de los hogares pobres. Un rasgo destacado de este tipo de hogares es que la pobreza infantil tiende a ser más rigurosa que la media de cada tipo de hogar. Además, si el hogar está encabezado por una mujer, el consumo equivalente se sitúa en un $83 \%$ del que tienen los encabezados por mujeres en el conjunto de las familias pobres (Oliver Alonso, ed., 2001). En un estudio posterior hecho con una metodología distinta Mercader también constató que familias monoparentales con menores a cargo presentan en Cataluña un riesgo elevado de pobreza monetaria y unos niveles de privación por encima de la media (Mercader, ed. 2004).

En Cataluña existe desde 1990 una Renta Mínima de Inserción (Programa Interdepartamental de la Renda Mínima d'Inserció, PIRMI), una iniciativa de la Generalitat de Catalunya para ayudar a todas aquellas personas o familias que no disponen de suficientes recursos para atender a sus necesidades más básicas, con el fin de prepararlas para su inserción social y/o laboral. Una parte importante de los destinatarios del PIRMI desde su creación son las familias monoparentales, que representan un 34\% del total de hogares beneficiados y que acogen en su seno el 57\% de los hijos a cargo. Las familias monoparentales que reciben la Renta Mínima de Inserción están encabezados por mujeres en un $98 \%$.

La mejor receta para combatir la pobreza es la creación de ocupación de calidad y la disminución de la precariedad en el empleo. La lucha contra la economía sumergida; la reducción de la tasa de temporalidad; la eliminación de discriminaciones en el mercado de trabajo como son el diferencial entre los salarios de hombres y mujeres o las elevadas tasas femeninas de desempleo; el establecimiento de unas prestaciones dignas de desempleo; el fomento de las políticas activas de mercado de trabajo que permitan el reciclaje ágil de los desempleados constituyen sin duda las mejores armas para evitar la exclusión social.

Como es bien sabido, uno de los problemas más acuciantes es el acceso a la vivienda debido no sólo al reciente aumento de su coste sino sobre todo de la ausencia de alternativas en forma de vivienda social de alquiler que existe en muchos países con Estados de bienestar más desarrollados. La Figura 9 sobre el gasto público en materia de vivienda nos muestra lo lejos que nos encontramos de las tendencias mayoritarias europeas. Para alcanzar la media europea se debería dedicar al menos el doble a programas de vivienda social (lo cual supondría reducir las desgravaciones fiscales para la adquisición de vivienda que, según algunos expertos, constituye uno de los factores de su encarecimiento). 


\section{Lluis Flaquer}

FiguRA 9. Gasto público en vivienda social. España y EU-15, 1980-2001

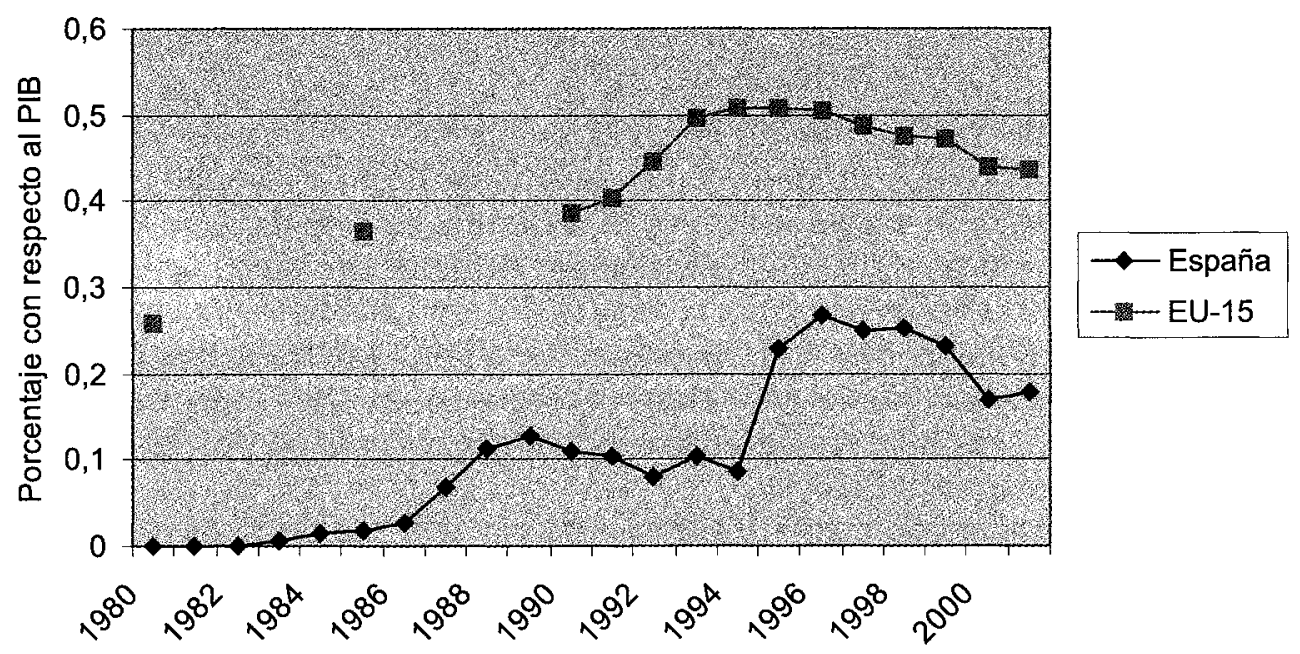

Fuente: Elaboración propia con datos de la OCDE.

De la misma forma, sería conveniente incrementar el gasto en programas para combatir la exclusión social, que bajo la administración del Partido Popular experimentó un importante retroceso, tras haber superado la media europea en los últimos gobiernos del PSOE (ver Figura 10).

Sin embargo, una de las dificultades con que tropieza a menudo el diseño de políticas sociales para luchar contra la pobreza infantil es que la escasez de datos conduce a la negación del problema. Una de las principales causas por las cuales esta cuestión todavía no se refleja agenda política es que resulta invisible para la mayoría de actores políticos y sociales implicados ante la ausencia de informaciones fiables. En el caso de España las deficiencias estadísticas en este apartado claman al cielo. Por ejemplo, el último dato español sobre la tasa coyuntural de divorcialidad de que dispone Eurostat es de 1995 . A causa de nuestro peculiar sistema en España tenemos distintas series estadísticas para las separaciones y para los divorcios, siendo las segundas las únicas que resultan homologables a nivel internacional. Pero eso no es todo. Para alimentar la ceremonia de la confusión el INE dispone dos tipos diferentes de datos sobre los flujos de separación y divorcio. Los datos de la primera serie, existente desde la aprobación de la Ley del Divorcio, son publicados anualmente por el Consejo General del Poder Judicial (CGPJ). Al ofrecer tal sólo las cifras absolutas de las separaciones y divorcios dictados en las diferentes comunidades autónomas, nos permite conocer la evolución de la 


\section{Monoparentalidad}

inestabilidad conyugal en España, pero en cambio no nos brinda ninguna información sobre las características de las uniones o de los ex esposos. Gracias a un convenio firmado en 1995 entre el Consejo General del Poder Judicial y el Instituto Nacional de Estadística disponemos de nuevos datos más pormenorizados sobre las nulidades, separaciones y divorcios al explotar este último organismo las informaciones de los expedientes según las características de los esposos. Sin embargo, este acuerdo ha dado unos frutos bastante insatisfactorios porque algunos tribunales de dejan de rellenar los boletines correspondientes. El resultado es que hay una diferencia importante entre los datos del CGPJ y del INE de tal forma que el número de casos de separaciones y divorcios registrados por el CGPJ es muy superior al que ofrece el INE. En 1998 tres de cada diez casos publicados por el CGPJ no fueron documentados por el INE. Además, las variaciones regionales son muy importantes de manera que las diferencias en los casos no documentados van desde el 56\% en las Islas Canarias hasta el $11 \%$ en el País Vasco. Por otra parte, el número de no respuestas para algunas de las preguntas es muy alto. Por ejemplo, en la provincia de Barcelona una de cada diez parejas que se separaban o divorciaban no dio información sobre la duración de su matrimonio. Ignoramos qué utilidad práctica tiene este conjunto de datos incompletos, dado que no hay garantías de que los casos o preguntas no documentados se distribuyan de una manera aleatoria.

FỊGURA 10. Gasto público en exclusión social España y EU-15, 1980-2001

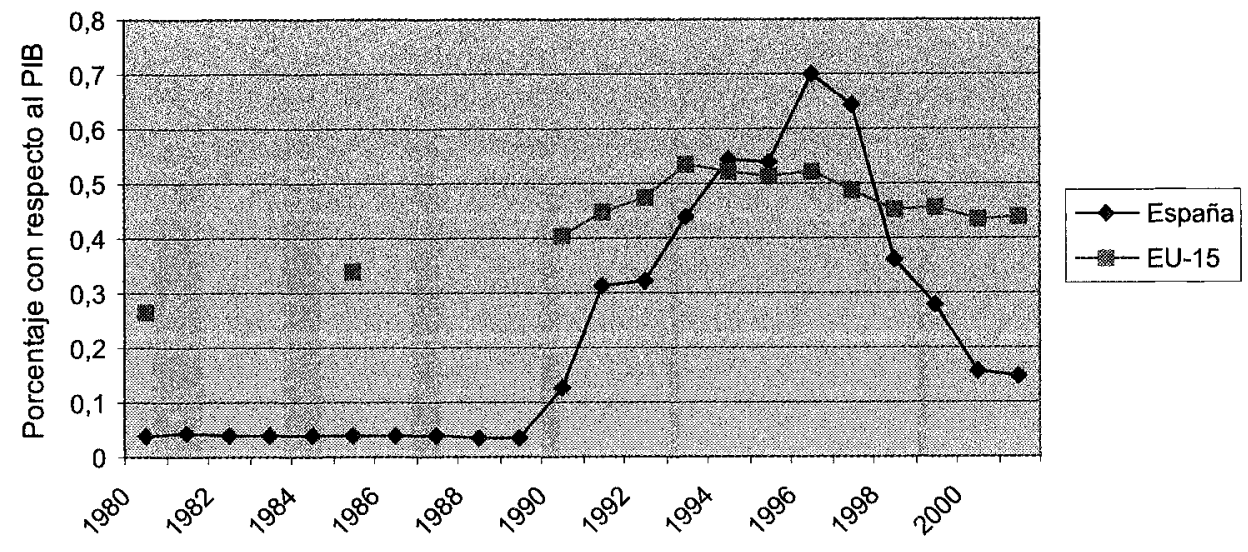

Fuente: Elaboración propia con datos de la OCDE. 


\section{Conclusiones}

Tanto si la hipótesis sobre la democratización del divorcio se confirma como si no, tenemos un problema. En caso positivo es muy probable que, en un futuro inmediato, la pobreza de las familias monoparentales vaya en aumento.

Como ya se ha dicho, el aumento de la actividad económica femenina, en sí un fenómeno deseable, relacionado con tanto con la prosperidad nacional como la de las familias, favorece también la tendencia a mayores tasas de ruptura. En caso de alcanzarse la meta propuesta por el Consejo Europeo de Lisboa (2000) de incrementar la tasa de ocupación femenina hasta el $60 \%$ probablemente crecería la inestabilidad conyugal, especialmente en los países del sur de Europa donde el empleo femenino tiene más margen para crecer.

Además, es muy posible que próximamente se incrementen las tasas de ruptura debido a otros factores. Así, la liberalización del divorcio que propone el PSOE (en el sentido de agilizarlo eliminado algunas de las restricciones actuales: compás de espera entre separación y divorcio)1 probablemente facilitará los trámites, hará aflorar muchas situaciones de hecho y hará subir las tasas (registradas) de divorcio.

Todo ello significa tener que dedicar mayores esfuerzos a luchar contra la exlusión social y contra la pobreza infantil. Pero es importante que las políticas sociales resuelvan problemas en vez de crear otros nuevos. En este sentido, sirvan de ilustración los efectos perversos que se han detectado a raíz del distinto tratamiento de las diversas situaciones de monoparentalidad por parte de las políticas sociales. El crecimiento de la diversidad familiar trae consigo una mayor necesidad de equidad en lo que respecta a los niveles de bienestar de todas las familias. No es aceptable que los niños tengan que experimentar mayores niveles de pobreza tan sólo por el hecho de vivir en un determinado tipo de familia.

Pero en el caso en que no se produjera una tendencia hacia un divorcio cada vez más interclasista también tenemos un problema porque ese escaso grado de individualización de las parejas españolas revelaría al fin y al cabo un déficit de ciudadanía. En este sentido, una de las conclusiones de este trabajo es que debemos ir más allá en la exploración de las relaciones existentes entre divorcio y derechos de ciudadanía. De la misma manera que el matrimonio puede ser conceptuado como un derecho de ciudadanía, el divorcio también lo debería ser. Cabría, pues, distinguir entre el acceso formal y el acceso real al divorcio y, en caso de que existiera una distancia entre ambos, averiguar las razones de ese déficit de- 


\section{Monoparentalidad}

mocrático, así como las barreras que entorpecen el ejercicio del derecho al divorcio. Este debate no tiene un carácter puramente académico o normativo. No cabe duda de que una parte importante de la violencia doméstica que se da en España es atribuible al escaso grado de individualización de las mujeres españolas. Si queremos, pues, eliminar esa lacra debemos seguir investigando sobre los determinantes del divorcio, así como los efectos que tiene la ruptura matrimonial sobre el bienestar de las personas involucradas.

\section{Bibliografía}

AlBerd, I. (1979). Historia y sociología del divorcio en España. Madrid: Centro de Investigaciones Sociológicas.

Alberdi, I., L. Flaquer y J. Iglesias de Ussel (1994). Parejas y matrimonios: Actitudes, comportamientos y experiencias. Madrid: Ministerio de Asuntos Sociales.

Almeda, E. (2004). Les famílies monoparentals a Catalunya. Perfils, necessitats i percepcions. Barcelona: Generalitat de Catalunya.

AlmedA, E. y L. FLAQUER (1995). "Las familias monoparentales en España: Un enfoque crítico». Revista Internacional de Sociologia. Núm. 11: 21-45.

ARchard, D. W. (2003). Children, Family and the State. Aldershot: Ashgate.

AtKInson, A. B. (2000). «Fighting Poverty: Towards a European Benchmark?». Paper contributed to the workshop on Fighting Poverty and Inequality through Tax-Benefit Reform: Empirical Approaches. Barcelona: 25-11-2000.

Barbagli, M. (1990). Provando e riprovando. Matrimonio, famiglia e divorzio in Italia e in altri paesi occidentali. Bologna: Il Mulino.

Barbagli, M. and C. Saraceno (1998). Separarsi in Italia. Bologna: Il Mulino.

BARNES, H. (2001). «How Other Countries Monitor thee Well-Being of Their Children?» In Bradshaw, J. (ed.) Poverty: The Outcomes for Children. Occasional Paper 26. London: Economic and Social Research Council/Family Policy Studies Centre/Social Policy Research Unit. pp. 215-236.

Beck, U. (1992). Risk Society: Towards a New Modernity. London: Sage.

BECK, U. and E. BECK-GERNSHEIM (2002). Individualization:Institutionalized Individualism and $I t s$ Social and Political Consequences. London: Sage.

Beck-Gernsheim, E. (2002). Reinventing the Family: In Search of New Lifestyles. Cambridge: Polity.

BECKER, GarY S. (1981). A Treatise on the Family. Cambridge, Mass. and London: Harvard University Press.

BÉgEOT, F. and J. A. FERNÁNDEZ-CoRdón (1997). «Demographic Convergence Beyond National Differences». En J. Commaille and F. de Singly eds. The European Family: The Family Question in the European Community. Dordrecht/Boston/London: Kluwer Academic Publishers. pp. 23-44.

BetTIO, F. and P. VILlA (1998). "A Mediterranean Perspective on the Breakdown of the Relationship between Participation and Fertility». Cambridge Journal of Economics 22: $137-71$. 
BLAIR, T. (1999). «Beveridge Revisited: A Welfare State for the 21st Century». En R. Walker (ed.). Ending Child Poverty: Popular Welfare for the 21st Century? Bristol: The Policy Press. pp. 7-18.

BORRAJo INIESTA, S. (1989). La ruptura matrimonial en España. Madrid: Eudema.

Bradshaw, J, C. Stimson, C. Skinner and J. Williams (1999). Absent Fathers? London and New York: Routledge.

BRADSHAW, J. (2000). "Child poverty in comparative perspective». En D. Gordon and P. Towsend (eds.). Breadline Europe: The Measurement of Poverty. Bristol. The Policy Press. pp. 223-250.

Bradshaw, J. (ed.) (2001). Poverty: The Outcomes for Children. Occasional Paper 26. London: Economic and Social Research Council/Family Policy Studies Centre/Social Policy Research Unit.

BRAmletT, M.D. and W.D. Mosher (2001). First Marriage Dissolution, Divorce, and Remarriage: United States. Advance date from vital and health satistics; No. 323. Hyattsville, Maryland: National Center for Health Statistics.

CABrillo, F. (1999). The Economics of the Family and Family Policy. Cheltenham, UK and Northampton, MA, USA: Edward Elgar.

Carrasco, C., A. Alabart, M. Mayordomo and T. Montagut (1997). Mujeres, trabajos y políticas sociales: Una aproximación al caso español. Madrid: Instituto de la Mujer.

Castles, F. G. (1998). Comparative Public Policy: Patterns of Post-War Transformation. Cheltenham: Edward Elgar.

CAstles, F. G. and M. Flood (1993). «Why Divorce Rates Differ: Law, Religious Belief and Modernity». In F. G. Castles ed. Families of Nations: Patterns of Public Policy in Western Democracies, Aldershot: Darmouth: 293-326.

Castles, F. G. ed. (1993). Families of Nations: Patterns of Public Policy in Western Democracies, Aldershot: Darmouth.

Castro Martín, T. and BumPass, L.L (1989). «Recent Trends in Marital Disruption». Demography 26 (1): 37-51.

Cherlin, A. (1978). «Remarriage as an Incomplete Institution». American Journal of Sociology. 84 (3): 634-650.

Cherlin, A. J. (1981). Marriage, Divorce, Remarriage. Cambridge, Mass.: Harvard University Press.

Comajuncosa, J., A. Escobedo, L. Flaquer, A. Laborda, C. Obeso, et. al. (2004). Informe Randstad. Calidad del trabajo en la Europa de los Quince: Las políticas de conciliación. Esade. Instituto e Estudios Laborales. Ver resumen en: http://webs.uvigo.es/ ccoo/pdf/estudios_randstad__2004_conciliación.pdf.

Cousins, C. (1999). Society, Work and Welfare in Europe. London: Macmillan.

DANZIGER, S. and J. WALDFOGEL (2000). «Investing in Children: What Do We Know? What Should We Do?». En S. Danziger and J. Waldfogel (eds.) Securing the Future: Investing in Children from Birth to College. New York: Russell Sage Foundation. pp. 1-15.

DUNCAN, S. and R. EDWARDS (1999). Lone Mothers and Paid Work. Basingstoke: Macmillan.

DunCAN, S. and R. Edwards (eds.) (1997). Single Mothers in an International Context: Mothers or Workers? Basingstoke: Taylor and Francis Ltd.

EekelaAR, John (1991). Regulating Divorce. Oxford: Clarendon Press.

EMERY, R. E. (1988). Marriage, Divorce and Children»s Adjustment. Newbury Park, Calif.: Sage.

Esping-ANDERsen, G. (1990). The Three Worlds of Welfare Capitalism. Cambridge: Polity Press. 


\section{Monoparentalidad}

Esping-Andersen, G. (1999). Social Foundations of Postindustrial Economies. Oxford: Oxford University Press.

EsPING-ANDERSEN, G. (2002). "A Child-Centred Social Investment Strategy». En G. Esping-Andersen et al. Why We Need a New Welfare State. Oxford: Oxford University Press. pp. 26-67.

European Commisston (2000). Presidency Conclusions. Lisbon European Council 23 and 24 March 2000.

EuRopean Commission (2002). European Social Statistics: Demography. Luxembourg: Office for Official Publications of the European Communities.

Eurostat (2000). Living Conditions in Europe. Statistical Pocketbook. 2000 Edition. Luxembourg: European Communities.

Fernández Cordón, J.A. y C. Tobío Soler (1998). «Las familias monoparentales en España». Revista Española de Investigaciones Sociológicas. Núm 22: 67-97.

FERnández Cordón, J.A. y C. Tobío SOLER (1999a). «Monoparentalidad, trabajo y familia». Revista Internacional de Sociología. Tercera Época. Núm. 22: 67-97.

Fernández Cordón, J.A. y C. Tobío SOler (1999b). Las familias monoparentales en España. Madrid: Ministerio de Trabajo y Asuntos Sociales.

Festy, P. (1988). «Après la séparation: Diversité et stabilité des comportements», Population 43: 517-536.

FlaqUeR, L (2000). «Is there a Southern European model of family policy?». En A. Pfenning and T. Bahle (eds.). Families and Family Policies in Europe. Franfurt a.m./New York: Peter Lang.

FlaqUER, L. and E. AlmEDA (en prensa). «Individualisation and divorce in the European Union». Social Politics.

FLAQUER, L. (1995). «El modelo de familia española en el contexto europeo». En S. Sarasa and L. Moreno eds. El Estado del bienestar en la Europa del Sur. Madrid: Consejo Superior de Investigaciones Científicas/ Instituto de Estudios Sociales Avanzados: 289-311.

FLAQUER, L. (1999). La estrella menguante del padre. Barcelona: Ariel.

FLAQUER, L. (2000). Las políticas familiars en una perspectiva comparada. Barcelona Fundación «la Caixa».

Flaquer, L. (2002). "Family Policy and the Maintenance of the Traditional Family in Spain». In A. Carling, S. Duncan and R. Edwards eds. Understanding Families: Morality and Rationality in Policy and Practice. London: Macmillan. pp. 84-92.

FlaqueR, L. (2003a). «Familia y Estado de bienestar en la Europa del sur». Arbor. Ciencia, pensamiento y cultura. Núm. 685. Madrid: CSIC. Pp. 195-220.

FlaqueR, L. (2003b). «Pobreza y familia». Arbor. Ciencia, pensamiento y cultura. Núm. 694. Madrid: CSIC. Pp. 327-342.

FlAQUER, L. (2003c). "Familia». Idees. Revista de temes contemporanis. Vol. 20: 213-233.

FlAQUER, L. (2004). «Llei de suport a les famílies: Una oportunitat perduda?» InDret. Working Paper de Dret Català Núm: 12.

Forssén, K. (1998). «Child Poverty and Family Policy in OECD Countries». LIS Working Paper Series No. 178. March. Luxembourg: LIS.

FurstenberG JR., F. F. and CherLin, A. J. (1991). Divided Families: What Happens to Children When Parents Part. Cambridge, Mass. and London: Harvard University Press.

GonZÁlez, M. del M y B. TRIANA (1998). "Divorcio, monoparentalidad y nuevos emparejamientos». En M. J. RodRigo y J. PALAcios (eds.) Familia y desarrollo humano. Madrid: Alianza. pp. 373-397. 
GONZÁLEZ-LÓPEZ, M. J. (2002). «A Portrait of Western Families: New Models of Intimate Relationships and the Timing of Life Events». En A. Carling, S. Duncan and R. Edwards eds. Analysing Families: Morality and Rationality in Policy and Practice. London: Routledge. pp. 21-47.

Goode, W. J. (1956). After Divorce. Glencoe, Ill.: The Free Press.

GoODE, W. J. (1970). World Revolution and Family Patterns. New York: The Free Press and London: Collier Macmillan Publishers (1st ed., 1963).

Goode, W. J. (1993). World Changes in Divorce Patterns. New Haven and London: Yale University Press.

Hamilton, C. and K. Standley (eds.) (1995). Family Law in Europe. London, Dublin, Edinburgh: Butterworths.

HARDEY, M. and G. CROW (eds.) (1991). Lone Parenthood: Coping with Constraints and Making Opportunities. New York and London: Harvester Wheatsheaf.

HART, N. (1976). When Marriage Ends: A Study in Status Passage. London: Tavistock Publications.

HERNÁNDEZ Rodriguez, G. (1996). Situación socio-económica das mulleres separadas en Galicia. Santiago de Compostela: Xunta de Galicia.

Houle, R., Simó, C., Solsona, M., and Treviño, R. (1999). «Análisis biográfico del divorcio en España». Revista Española de Investigaciones Sociológicas. Núm. 88: 11-35.

IGLESIAS DE USSEL, J. et al. (1994). "Familia». In M. Juárez ed. V Informe sociológico sobre la situación social en España. Madrid: Fundación Foessa, vol 1: 416-547.

Institut d'EstadístiCA DE CATALUNYA (1997). Llars i famílies a Catalunya 1991. Barcelona: Generalitat de Catalunya.

Institut d'Estadística de Catalunya (2000). Llars i famílies a Catalunya 1996. Barcelona: Generalitat de Catalunya.

JÄNTTI, M. and S. DANZIGER (2000). «Income Poverty in Advanced Countries». En A. Atkinson and F. Bourguignon (eds.) Handbook of Income Distribution. Amsterdam: Elsevier.

LEwIS J. with B. HoBSON (1997). «Introduction». En J. LEwIS (ed.) Lone Mothers in European Welfare Regimes: Shifting Policy Logics. London and Philadelphia: Jessica Kingsley Publishers. pp. 1-20.

LEWTS, J. (1992). «Gender and the Development of Welfare Regimes». Journal of European Social Policy 2 (3).

LewIS, J. (1993). «Introduction: Women, Work, Family and Social Policies in Europe». En J. Lewis, (ed.) (1993). Women and Social Policies in Europe. London: Edward Elgar, pp. 1-24.

LEwIS, J. (1997). «Lone Mothers: The British Case». En J. Lewis (ed.) Lone Mothers in European Welfare Regimes: Shifting Policy Logics. London and Philadelphia: Jessica Kingsley Publishers, pp. 50-75.

LEwIS, J. (1999). «The «Problem» of Lone Motherhood in Comparative Perspective». En J. Clasen (ed.) Comparative Social Policy: Concepts, Theories and Methods. Oxford: Blackwell. pp. 181-199.

LEWIS, J. (2001). The End of Marriage. Individualism and Intimate Relations. Cheltenham: Edward Elgar.

LEwIS, J. (2002a). «Gender and Welfare State Change». European Societies 4 (4): 331-357.

LEWIS, J. (2002b). «Individualisation, Assumptions about the Existence of an Adult Worker Model and the Shift towards Contractualism». En A. Carling, S. Duncan and R. Edwards (eds.) Analysing Families: Morality and Rationality in Policy and Practice. London: Routledge. pp. 51-63. 


\section{Monoparentalidad}

LEwIS, J. (ed.) (1993) Women and Social Policies in Europe. London: Edward Elgar.

LEWIS, J. (ed.) (1997). Lone Mothers in European Welfare Regimes: Shifting Policy Logics. London and Philadelphia: Jessica Kingsley Publishers.

LewIS, J. (ed.) (1998). Gender, Social Care and Welfare State Restructuring in Europe. Aldershot: Ashgate.

LÓPEZ PINTOR, R. y J. J. TOHARIA (1989). Separación y divorcio en España: Un informe sociológico. Madrid: Ministerio de Trabajo y Seguridad Social.

MARTIN, C. (1997). L»après divorce: Lien familial et vulnerabilité. Québec: PUL.

MeIL LANDWERLin, G. (1999). La postmodernización de la familia española. Madrid: Acento Editorial.

MerCADER, M. (ed.) (2004). La pobresa a Catalunya. Informe 2003. Barcelona: Fundació Un Sol Món-Caixa de Catalunya.

Micklewright, J. and K. STEWART (1999). "Is the Well-Being of Children Converging in the European Union?» Luxembourg: LIS.

MILLAR, J. (1999). «Sate, Family and Personal Responsibility: The Changing Balance for Lone Mothers in the United Kingdom». En G. Allan (ed). The Sociology of the Family. Oxford: Blackwell. pp. 247-261.

Moreno Mínguez, A. (2000). «Las familias monoparentales en España». Revista Internacional de Sociología. Tercera Época. Núm. 26: 39-63.

MorRison, D.R. and A. Ritualo (2000). «Routes to Children»s Economic Recovery After Divorce: Are Cohabitation and Remarriage Equivalent?» American Sociological Review 65: 560-580.

Naldini, M. (2003). The Family in the Mediterranean States. London/Portland, Or.: Frank Cass.

OECD (2002). Education at a Glance: OECD Indicators 2002. Paris: OECD.

Oliver Alonso, J. (ed.) (2001). La pobresa a Catalunya. Informe 2001. Barcelona: Fundació Un Sol Món-Caixa de Catalunya.

OrLOFF, A. S. (1993). «Gender and the Social Rights of Citizenship: The Comparative Analysis of Gender Relations and Welfare States». American Sociological Review. 58 (3): 303-328.

PFAU-EFFINGER, B. (2002). «Changing welfare states and labour markets in the context of European gender arrangaments». En J. G. Andersen and P, H. Jensen (eds.) Changing Labour Markets, Welfare Policies and Citizenship. Bristol: The Policy Press. pp. 235-256.

Phillips, R. (1988). Putting Asunder: A History of Divorce in Western Society. Cambridge: Cambridge University Press.

PRINGLe, K. (1998). Children and Social Welfare in Europe. Buckingham and Philadelphia: Open University Press.

REDMOND, G. (2000). «Children in Large Families: Disadvantaged or Just Different?» LIS Working Paper Series No. 225. Luxembourg: LIS.

Ringen, S. (1997). Citizens, Families, and Reform. Oxford: Clarendon Press.

RocA, E. (1999). Familia y cambio social (De la «casa» a la persona). Madrid: Civitas.

RojAs MARCos, L. (1994). La pareja rota: Familia, crisis y superación, Madrid: Espasa Calpe.

RousseiL, L. (1980). «Mariages et divorces. Contribution à une analyse systématique des modèles matrimoniaux". Population 3: 1025-1040.

Roussel, L. (1989). La famille incertaine. Paris: Éditions Odile Jacob.

Roussel, L. (1993). «Sociographie du divorce et divortialité». Population 48: 919-938. 
RUIZ BeCERRIL, D. (1999). Después del divorcio: Los efectos de la ruptura matrimonial en España, Madrid: Siglo XXI.

SARDON, J.P. (1986). «Évolution de la nuptialité et de la divortialité en Europe depuis la fin des années 1960». Population 41.

SARDON, J.P. (1996). «L'évolution du divorce en France». Population (3): 717-750.

SMART, C. (2002). "From Children»s Shoes to Children»s Voices». Paper contributed to the seminar on The Children of Divorce: Parentage and Citizenship. Barcelona: 19-20 September 2002.

Solsona, M., R. Houle, and C. Simó (2000). «Separation and Divorce in Spain». En M.J. González, T. Jurado and M. Naldini eds. Gender Inequalities in Europe: Women, Work and Welfare in the 1990s. London and Portland, Or.: Frank Cass: 195-222.

Spanter, G. B. and Thompson, L. (1984). Parting: The Aftermath of Separation and Divorce, Beverly Hills, London and New Delhi: Sage.

Stone, L. (1992). Road to Divorce: England 1530-1987. Oxford: Oxford University Press.

Therborn, A G. (2004). Between Sex and Power: Family in the World, 1900-2000. London and New York: Routledge

ThÉRY, I. (1993). Le démariage. Paris: Odile Jacob.

VleminckX, K. and T. M. Smeedrng (eds.) (2001). Child Well-Being, Child Poverty and Child Policy in Modern Nations: What Do We Know? Bristol: The Policy Press.

Wallerstein, J and S. BlaKesleE (1989). Second Chances. London: Bantam.

WALKER. R. (ed.) (1999). Ending Child Poverty: Popular Welfare for the 21st Century? Bristol: The Policy Press.

WeItzman, L. J. (1985). The Divorce Revolution: The Unexpected Social and Economic Consequences for Women and Children in America. New York: The Free Press and London: Collier Macmillan.

\section{Notas}

1 Ver declaraciones de Juan Fernando LÓPEz AguILAR, Ministro de Justicia, El País del lunes 17 de mayo de 2004, p. 21.

${ }^{2}$ Dicho método es el utilizado por Castles para verificar hasta qué punto se da un proceso de convergencia entre las variables utilizadas en su estudio en los últimos años. El coeficiente de variación de una distribución de frecuencias consiste en la desviación típica expresada como porcentaje de la media aritmética. Este coeficiente es útil para comparar la dispersión de dos o más distribuciones de frecuencias con diferentes medias aritméticas. En la comparación de dos variables un bajo coeficiente de variación indica que la dispersión es menor. El aumento del coeficiente de variación a lo largo del tiempo significa que los casos comparados se parecen cada vez menos, mientras que un descenso del coeficiente indica que se parecen cada vez más (Castles, 1998). 